\title{
A new method to assess spatial variations of outdoor thermal comfort: onsite monitoring results and implications for precinct planning
}

\author{
*Jianlei Niu ${ }^{1,2}$ and Jianlin Liu ${ }^{1}$, Tsz-cheung Lee ${ }^{3}$, Zhang(John) Lin ${ }^{4}$, Cheukming Mak ${ }^{1}$, Kam- \\ Tim Tse ${ }^{5}$, Bo-sin Tang ${ }^{6}$, Kenny C.S. Kwok ${ }^{7}$ \\ ${ }^{1}$ Department of Building Services Engineering \\ The Hong Kong Polytechnic University \\ Hunghom, Kowloon, Hong Kong \\ ${ }^{2}$ School of Thermal Engineering, \\ Shandong Jianzhu University, Jinan, China \\ ${ }^{3}$ Hong Kong Observatory \\ ${ }^{4}$ Division of Building Science and Technology, \\ City University of Hong Kong \\ ${ }^{5}$ Dept of Civil \& Environmental Engineering, The \\ Hong Kong University of Science and Technology \\ ${ }^{6}$ Department of Urban Planning \& Design, The \\ University of Hong Kong \\ ${ }^{7}$ Institute for Infrastructure Engineering, University \\ of Western Sydney \\ *Corresponding author: Bejlniu@polyu.edu.hk
}

\begin{abstract}
Residents wish to have outdoor spaces to enjoy walking, cycling, and other recreational activities, which are often hindered by the unfavorable thermal comfort conditions, especially in the summer. High building densities lower the average wind speed and this intensifies the urban heat island effects at city scale. The conscientious use of building morphology to create local thermal comfort zone at selected spots in a large precinct is becoming a pressing issue for sustainable urbanization. This paper is a proof of concept study via continuous monitoring of the pedestrian level winds and thermal parameters at two sample days in summer, which include instantaneous air temperature, globe temperature, wind speed and humidity. Three outdoor locations at an university campus are chosen and daytime thermal perceptions at the three sites were evaluated using PET (Physiological equivalent temperature). A PET based new index was defined, which is called the thermally-perceivable environmental parameter difference, respectively for the radiant temperature and wind speed. By analyzing the simultaneous differences of radiant temperature, wind speed and air temperature between the monitored spots, it is shown that it was the wind speed and radiant temperature differences that were making significant differences in thermal comfort. This pilot study clearly indicates that wind amplification combined with shading effects can generate thermally comfortable conditions in the open ground floor beneath an elevated building, even on a sunny, hot summer day in a subtropical city. This finding helps to alert city planners of additional options available in precinct planning to encourage outdoor activities.
\end{abstract}


Keywords: Outdoor thermal comfort; built environment; microclimatic parameters; physiological equivalent temperature (PET)

\section{Introduction}

City residents normally spend much time indoors without enjoying the outside natural wind and sunshine. Statistical surveys report that outdoor recreational activities such as walking and cycling benefit both physiological and psychological health [1,2]. Meanwhile, more time spent outdoors effectively reduces the building energy consumption for air conditioning and artificial lighting, especially in hot and humid regions. Gehl [3] proposed that public spaces should be made more livable for the citizens and his study revealed that sensitive bench positioning in relation to sun and shade had an impact on the popularity of a public space. In recent decades, more and more researchers have considered designing outdoor places to be more attractive to citizens and proposing this a goal for urban planning and building design [4-6].

The outdoor built environment (created by the arrangements of building clusters) has modified the surrounding microclimate in a city. For the urban scale (10km 100km) [7], the urban heat island (UHI) effects are well known, and the establishment of better microclimates for residents is now a great challenge [8]. Li et al. [9] proposed the concept of city ventilation and showed the analysis that the thermally driven flows and building surfaces flows can remove airborne pollutants and the exhaust heat released from the buildings in a high-rise dense city. The Air ventilation assessment (AVA) scheme of the Hong Kong SAR government [10] serves as a policy and technical guideline [11] for urban planning and building design. The core recommendation in this AVA guideline is to amplify pedestrian level wind in Hong Kong. Givoni et al. [5, 12] proposed that urban wind amplification can be obtained by appropriate arrangements of high-rise and low-rise building blocks. The height differences create complicated wind flow patterns around buildings to arouse different wind speeds at different local areas such as the "street canyon" formed between buildings. For hot climates, wind is very much desirable for summer comfort.

During past decades, many researchers have investigated urban scale bio-meteorology and city climatology for the purpose of outdoor thermal comfort evaluation for different climatic zones of the world [13-17]. Most of these studies employed field measurements and survey of outdoor thermal parameters and human behaviors in urban districts [14, 18-21]. A few researchers evaluated outdoor thermal comfort by numerical simulations [22-24].

The choice of a bio-meteorology index for outdoor thermal assessment has been a special research topic. The indices were mainly divided into two types based on their assumptions, empirical studies and the heat budget model of human body. Nagano and Horikoshi [25] summarized these indices and presented their availabilities for different problems. The OUT_SET $^{*}[26,27]$ transferred from the standard effective temperature $\left(\right.$ SET $\left.^{*}\right)$ of indoor version [23] for the outdoor use by simplifying the complicated radiation environment into "standard" environment was an empirical index. The other indices which were obtained based on physiologically modeled relationships were the PMV(Predicted Mean Vote) model by Fanger (1972)[28] and the PMV $^{*}$ model further developed for outdoor use by Gagge et al.(1986) [29]. Another typical and frequently used index, physiological equivalent temperature(PET), was introduced by Höppe [30] for outdoor thermal comfort evaluation, which was based on the Munich energy-balance model for individuals (MEMI), and PET for different grades of thermal perception in Western and Middle Europe had been presented. Meanwhile, Lin and Matzarakis 
[31] reported different PETs value for the neutral condition in subtropical Taiwan region, based on the climatic data analysis and tourists' surveying results (Table 1). It had shown that people in Taiwan were more sensitive to the thermal environmental parameter changes. In addition, UTCI (Universal thermal climate index), which was proposed more recently, was a more complex heat budget based approach and was increasingly used by bio-meteorological researchers [32, 33]. Other methods for assessing human thermal responses to local thermal environment are the Index of thermal stress (ITS) [12] and the COMFA outdoor thermal comfort model [34].

\section{Table 1}

$P M V$ and PET for different grades of thermal perception and physiological stress on human beings in Taiwan and Western/Middle European ranges [31, 35]

\begin{tabular}{ccccc}
\hline PMV & $\begin{array}{c}\text { PET range for } \\
\text { Taiwan }\left({ }^{\circ} \mathrm{C}\right)\end{array}$ & $\begin{array}{c}\text { PET range for } \\
\text { Western/Middle } \\
\text { European }\left({ }^{\circ} \mathrm{C}\right)\end{array}$ & Thermal perception & $\begin{array}{c}\text { Grade of } \\
\text { physiological stress }\end{array}$ \\
\hline-3.5 & 14 & 4 & Very cold & Extreme cold stress \\
-2.5 & 18 & 8 & Cold & Strong cold stress \\
-1.5 & 22 & 13 & Cool & Moderate cold stress \\
-0.5 & 26 & 18 & Comfortable(Neutral) & No thermal stress \\
0.5 & 30 & 23 & Slightly warm & Slight heat stress \\
1.5 & 34 & 29 & Warm & Moderate heat stress \\
2.5 & 38 & 35 & Hot & Strong heat stress \\
3.5 & 42 & 41 & Very hot & Extreme heat stress \\
\hline
\end{tabular}

Field measurement has been the main method used for evaluating the micro-climate and outdoor thermal comfort, as reported by Nikolopoulou et al. [13, 14] and Mayer et al. [36] for Western European country comparisons, Ali-Toudert et al. [16] and Johansson [18] for hot dry climates, Lin et al. [15, 37] and Johansson et al. [19] for hot and humid climates, and Bauche et al. [31] for a cold climate where PET was lower than 0 in a Russian city. Some previous Asian urban micro-climate researchers were also very active, for instance, $\mathrm{Ng}$ et al. [11] investigated urban human thermal comfort in Hong Kong, Lin and Hwang [37, 38] in Taiwan, Thorsson et al. [21] and Knez et al. [39] investigated Japanese urban public places, Jeong et al. [40] conducted similar studies in Korea; and for Mainland China, there were related investigations in Nanjing [41], Wuhan [42, 43] and Tianjin [44].

Studies on a few typical outdoor spaces, which were known to have their own microclimate, have been reported. Lin [15] investigated the thermal relationship between perception and numbers of people in a public square. Ail-Toudert et al. [45, 46] and Hwang et al. [47] investigated the impact of canyon orientations and vegetative shading in street canyons. Some semi-outdoor environments such as a railway station, municipal cultural center, art center and museums have been investigated by Hwang et al. [48] and Zhou et al. [42], and it was suggested that shading design improves outdoor thermal comfort by shielding the solar radiation. Measurements in a public park $[38,39,49,50]$ revealed that shading level affects the number of 
visitors, because of better thermal comfort, in the resting places. In addition, shading provided by trees and buildings in a large, open campus $[20,51]$ was found to significantly improve thermal comfort in summer.

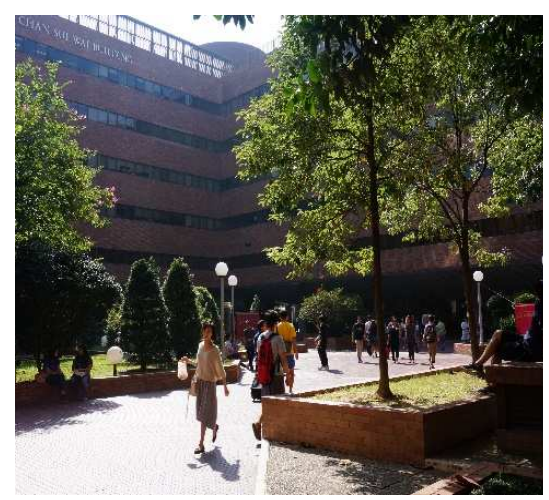

(1) Site 1

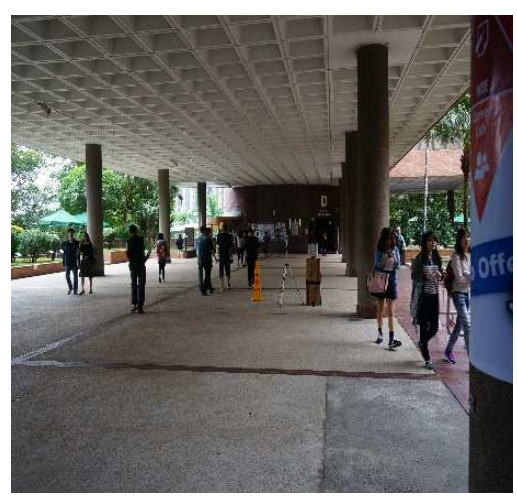

(2) Site 2

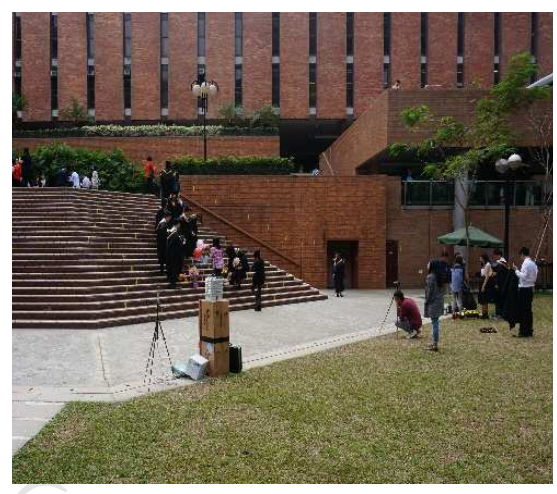

(3) Site 3

Fig. 1. Photos of three selected sites at an university campus.

Reviewing these studies on how built environment design can significantly modify the local, also called micro-environmental, wind and thermal comfort conditions by means of wind amplification/attenuation and solar radiation/shading effects, a hypothesis is established that, although high building densities lower the average wind speed and intensifies the urban heat island (UHI) effects at city scale, the conscientious use of building morphology to create local thermal comfort zone at selected spots in a large precinct is very possible. Specifically, for hot and humid climates, shading is desirable; the downwash from a high-rise building can be 'funneled' to the intended spots. This hypothesis is based upon the authors' observations of some landmark building designs. One example is shown in Fig.1 - the open ground floor formed beneath the elevated building blocks in our university campus. It is proposed that creating such thermally comfortable spots in a precinct via the integration of several architectural features could become a design objective in urban and community planning, be significant for public health, enhancing perceived livability of a city, and fulfilling the aims of sustainable urbanization. The objective of this paper is to reveal the local differences in thermal perceptions that exist in practice, via simultaneous onsite monitoring of environmental parameters at the pedestrian level at three selected sites in a precinct. This study serves as a proof of concept or performance testing study.

\section{Methodology}

\subsection{On-site monitoring}

The architectural layout of an existing campus is taken as a prototype design, and three different sites at the campus have been chosen as the testing samples. The thermal environmental parameters that are known to affect the thermal comfort of pedestrians were monitored continuously for two sample days at these three selected sites, and differences in thermal comfort status between these three sites are identified.

The three sites are shown in Fig. 1: 1) an open space receiving direct and multiple reflections of solar radiation from the surrounding buildings, 2) the open ground level beneath an elevated building block, and 3) a below ground level open space surrounded by building blocks. 
Specifically, the first site is an open ground subject to direct solar radiation and multiple solar reflections from the neighbouring buildings (Fig.1. (1)). Anecdotal evidence suggest that for most of the time in a year, this site is too warm, hence discouraging its use. Site 2 is well shaded, and also acts as a corridor for wind, therefore a preferred spot in summer. This site is frequently used for formal business activities such as exhibitions and receptions, staff and student communal activities such as open forums and dancing, Taichi or martial-arts classes and practices. Site 3 is an open lawn area in the campus, utilizing a lowered area below the campus podium (Fig.1.(3)). It is subjected to direct solar radiation most of the time and discouraged its using under the hot and humid lengthy Hong Kong summer.

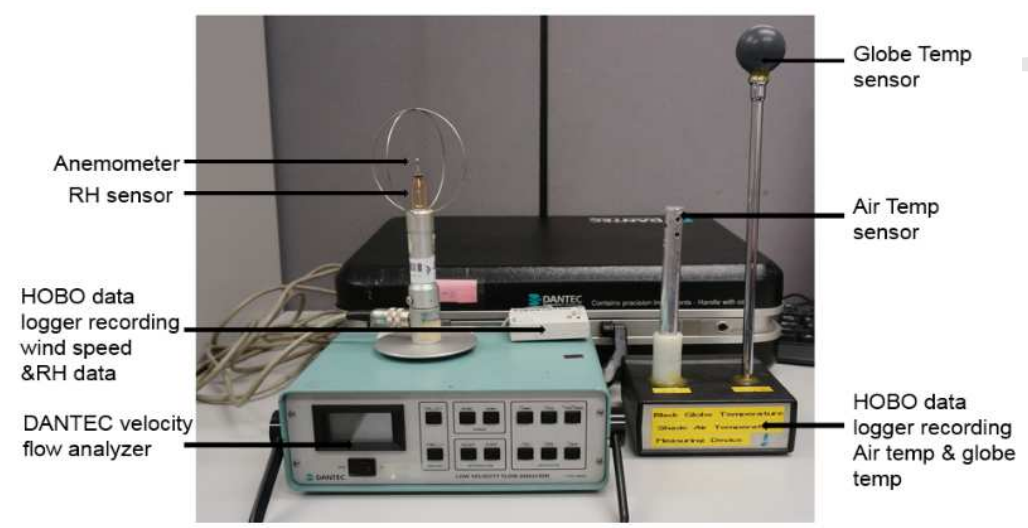

Fig. 2. Instruments used for the investigation.

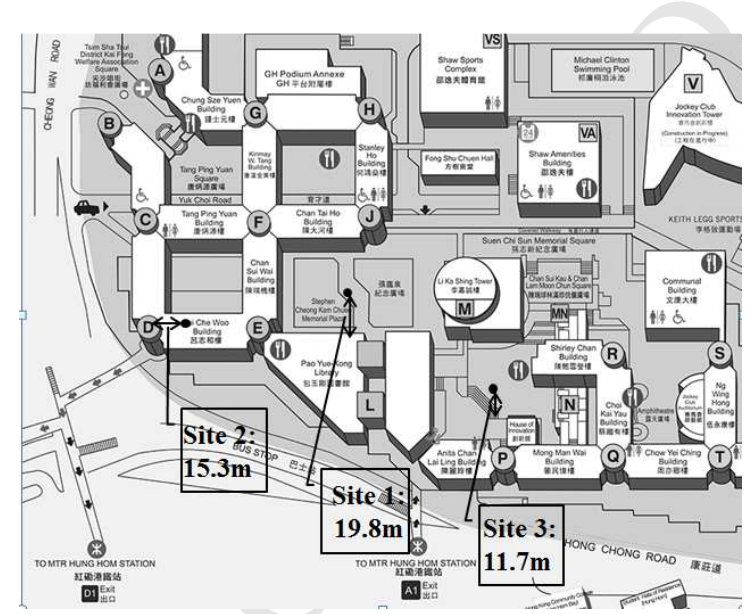

(1) Horizontal plane of the investigation sites

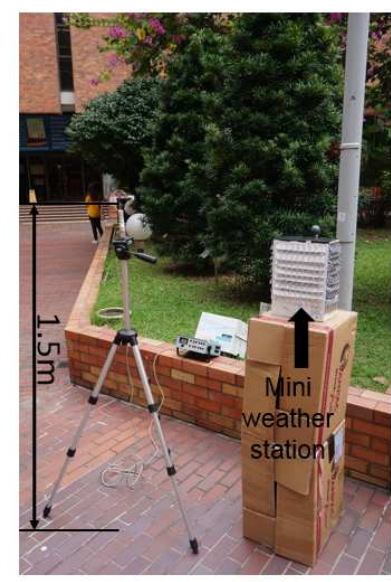

(2) Vertical height from the ground

Fig. 3. Locations of mini weather stations at investigation sites.

Hong Kong is located in a sub-tropical climate zone, winter is short and relatively mild, and summer comfort is more important than that in winter, and therefore this preliminary study was conducted in the summer. Three mini weather stations were simultaneously used, one each at the three sites, with sensors to measure the following environmental parameters: air temperature $\left(T_{a},{ }^{\circ} \mathrm{C}\right)$, globe temperature $\left(T_{g},{ }^{\circ} \mathrm{C}\right)$, wind speed $\left(V_{a}, \mathrm{~ms}^{-1}\right)$ and relative humidity $(R H, \%)$ at two 
sample days: one sunny day and one cloudy day in June, 2014. All instruments (Fig. 2) were compliant with the ISO 7726 standard [52]. The mini weather stations were located at the pedestrian level, 1.5 metres above the ground and the shortest distance from the building vertical walls were $19.8 \mathrm{~m}, 15.3 \mathrm{~m}$ and $11.7 \mathrm{~m}$ for sites 1,2 and 3 , respectively (Fig. 3). Table 2 shows the measurement ranges and accuracy of the probing sensors used in this study. Data logging was taken at 5 minutes intervals from 09:00 to 18:00 for all parameters. All instruments were pretested and calibrated before the investigations.

Table 2

Measurement ranges of environmental sensors used in this study

\begin{tabular}{cccc}
\hline Environmental parameter & Sensor & Range & Accuracy \\
\hline Air temperature $\left(T_{a}\right)$ & Shaded air temperature measuring device & $-30 \sim 50\left({ }^{\circ} \mathrm{C}\right)$ & $\pm 0.5^{\circ} \mathrm{C}$ \\
Globe temperature $\left(T_{g}\right)$ & Black globe temperature measuring device & $-30 \sim 50\left({ }^{\circ} \mathrm{C}\right)$ & $\pm 0.5^{\circ} \mathrm{C}$ \\
Wind speed $\left(V_{a}\right)$ & Anemometer and DANTEC velocity analyzer & $0.25 \sim 5\left(\mathrm{~ms}^{-1}\right)$ & $\pm 0.25 \mathrm{~ms}^{-1}$ \\
Relative humidity $(\mathrm{RH})$ & Hygrometer & $0 \sim 100(\%)$ & $\pm 1 \%$ \\
\hline
\end{tabular}

\subsection{Data analysis method}

(1) Differences in thermal comforts

Thermal comfort is estimated from the measured objective environmental parameters rather than human subject based survey. The universally applicable models take into account all basic thermo-regulatory processes, such as the constriction or dilation of peripheral blood vessels and the physiological sweat rate [53]. They enable the user to estimate "real values" of thermal conditions of the body, i.e. skin temperature, core temperature, sweat rate or skin wetness. The Munich energy balance model for individuals (MEMI) [30, 53] is such a thermo-physiological heat balance model. It is the basis for the calculation of the physiologically equivalent temperature (PET).

The PET model uses the following meteorological parameters [30, 35] as input: air temperature $T_{a}$, mean radiant temperature $T_{m \mathrm{rt}}$, wind speed $V_{a}$, relative air humidity $R H$, and in addition thermos-physiological parameters such as heat resistance of clothing $I_{c l o}$ and activity of humans $M$ (in Watts) are required. PET is adopted in the German guideline VDI 3787 [54] for outdoor environment evaluation, and free software, such as RayMan $[55,56]$, is available. $T_{m \mathrm{rt}}$ is calculated from the measured globe temperature by the following formula[52]:

$$
T_{m r t}=\left[\left(T_{g}+273\right)^{4}+\frac{1.10 \times 10^{8} \times V_{a}^{0.6}}{\varepsilon D^{0.4}}\left(T_{g}-T_{a}\right)\right]^{1 / 4}-273
$$

where $\varepsilon$ is emissivity of the globe, and $D$ is the globe diameter in this investigation. When analyzing the sampled data, PET values for all three sites are calculated, and the PET difference between any two sites at the same instant were calculated and compared.

(2) Identification of the causal environmental parameters

According to the illustrated correlation between PET and human perception of thermal comfort by Matzarakis et al. (in Table 1, internal heat production: $80 \mathrm{~W}$, heat transfer resistance of the clothing: 0.9 clo), a $2.5{ }^{\circ} \mathrm{C}$ (when PET is below $23^{\circ} \mathrm{C}$ ) or $3{ }^{\circ} \mathrm{C}$ (when PET is above $23{ }^{\circ} \mathrm{C}$ ) difference in PET value would mean a significant difference in thermal perception (with a PMV 
value difference of 0.5) [35]. To be able to identify which environmental parameters caused the differences of PET between any two sites, we define three new indices based upon the PET model, which are called thermally-perceivable environmental parameter differences, respectively for air temperature, radiant temperature and wind speed. More specifically, a thermallyperceivable radiant temperature difference, $\Delta T_{\mathrm{mrt}, 0.5}$, is defined as the mean radiant temperature change that can cause a PET change of $2.5{ }^{\circ} \mathrm{C}$ (when PET is below $23{ }^{\circ} \mathrm{C}$ ) or $3.0{ }^{\circ} \mathrm{C}$ (when PET is above $23{ }^{\circ} \mathrm{C}$ ) from the comfortable base condition [35] when $T_{a}=T_{m r t}=23{ }^{\circ} \mathrm{C}$ and $V_{a}=0.1$ $\mathrm{m} / \mathrm{s}$. It is obtained from the following procedure: by keeping constant the vapor pressure $12 \mathrm{hPa}$, internal heat production of $80 \mathrm{~W}$, the clothing level of 0.9 clo and any two of the three testing parameters $\left(T_{a}, T_{m r t}\right.$ and $\left.V_{a}\right)$, change the value of the other one testing parameter to obtain a different thermal perception level as described in Table 1, using RayMan calculation. For example, by keeping $\mathrm{T}_{\mathrm{a}}=23^{\circ} \mathrm{C}, \mathrm{V}_{\mathrm{a}}=0.1 \mathrm{~m} / \mathrm{s}$ and changing $\mathrm{T}_{\text {mrt }}$ values to $28.5^{\circ} \mathrm{C}$, the $P E T$ values change to $26^{\circ} \mathrm{C}$, which corresponds to the $P M V$ level of 0 . Thus the thermally perceivable $\Delta T_{m r t, 0.5}$ is found to be $5.5^{\circ} \mathrm{C}(=28.5-23)$ when PET is above $23{ }^{\circ} \mathrm{C}$. Thermally-perceivable air temperature difference $\Delta T_{a, 0.5}\left(=6^{\circ} \mathrm{C}\right)$ and thermally-perceivable wind speed difference $\Delta V_{a, 0.5}(=$ $-1.3 \mathrm{~m} / \mathrm{s}$ ) can be calculated similarly when PET is above $23{ }^{\circ} \mathrm{C}$. Between any two sites monitored, the instantaneous environmental parameter differences are calculated, and then normalized as follows. For the air temperature:

$$
\Delta \theta_{T_{a, 2-1}}=-\Delta T_{a, 2-1} /\left|\Delta T_{a, 0.5}\right|
$$

where the $\Delta T_{\mathrm{a}, 2-1}$ is the air temperature difference between the test site 2 and site 1 . A $\Delta \theta_{T a, 2-1}$ value greater than one would indicate that the air temperature has significantly affected the thermal perception between the two sites.

Similarly, for mean radiant temperature and wind speed, the normalized differences between any two sites 1 and 2 can be obtained via:

$$
\begin{gathered}
\Delta \theta_{T_{m r t, 2-1}}=-\Delta T_{m r t, 2-1} /\left|\Delta T_{m r t, 0.5}\right| \\
\Delta \theta_{V_{a, 2-1}}=\Delta V_{a, 2-1} /\left|\Delta V_{a, 0.5}\right|
\end{gathered}
$$

The negative signs are added in Equations (2) and (3) so that for all the three normalized environmental parameters, a positive value will mean that the environmental parameter is making Site 2 cooler than Site 1. On the other hand, an absolute value greater than one would indicate that the radiant temperature or the wind has significantly affected the thermal perception between the two sites. More indicative is the relative magnitude of the three normalized indices, $\Delta \theta_{T a, 2-1,} \Delta \theta_{T m r t, 2-1,} \Delta \theta_{V a, 2-1}$, which can be directly compared because their values have been normalized against their respective perceivable difference. The greater the magnitude of $\Delta \theta$, the more a major factor of the environmental parameter. It is expected that the methodology developed can be used for future analysis where vegetation and/or water surfaces present may generate strongly local ambient moisture differences, and this method will be supplementary to the other existing indices such as SET* [57].

As will be illustrated in section 3.2, the thermally-perceivable environmental parameter differences can vary with the base conditions. For a more accurate estimation $\Delta \theta_{T a, 2-1}, \Delta \theta_{T m r t, 2-1}$, 
and $\Delta \theta_{a, 2-1}$, the thermally-perceivable environmental parameter differences $T_{a, 0.5}, T_{m r t}, 0.5$ and $V_{a, 0.5}$ in Equations (2), (3) and (4) can be calculated using the actual measured conditions of Site 1 as the base condition.

\section{Results and Discussions}

\subsection{Simultaneous environmental parameters monitored}

Shown in Fig. 4 are the variations of air temperature, globe temperature and wind speed monitored during the two study days and the annual mean wind speed of at Hong Kong. In addition, large variations are visible in the monitored air temperature and globe temperature before 10:00am, because the instruments were being moved from indoors to the measured sites, and therefore data taken before 10:00 am are excluded in the later analysis. It should be noted that the difference between the two study days are obvious, but this is not the interest of this study. Rather the differences between the three sites on the same day are the focuses. Globe temperature $T_{g}$ on both Site 1 and Site 3 are much higher than that on Site 2 on both the sunny and cloudy days, whereas the wind speed $V_{a}$ at Site 2 is much higher, frequently exceeding the 5 $\mathrm{m} / \mathrm{s}$ upper bound of the anemometer while the wind speeds at Sites 1 and 3 fluctuated between 1 and $2 \mathrm{~m} / \mathrm{s}$. These wind speeds at Sites 1 and 3 are lower than the annual mean wind speeds recorded in the two urban weather stations (King's park and Hong Kong observatory) in recent years, which are about 2 to $3 \mathrm{~m} / \mathrm{s}$, whereas the $V_{a}$ at Site 2 frequently exhibits higher values (Fig. 4 (5)). It should be cautioned that this direct comparison between the two day sample data and annual average is subject to probability questioning, and that the simultaneous difference between the magnitude of the wind speed at Site 2 and those at the other two sites is a more direct evidence that funnel effects occur at the pedestrian level.

It appears that there are differences in the air temperatures, which are about 1 or $2{ }^{\circ} \mathrm{C}$ between the three sites on the sunny day, presumably caused by the radiation effect, though radiation-shield instrument boxes were used to minimize this effect. On the sunny day, the maximum globe temperature difference between Site 2 and the other two sites is about $8{ }^{\circ} \mathrm{C}$. Meanwhile, it should be noted that relative air humidity, though is monitored and has been shown in Fig.4.(6), is not included for further analysis, with the consideration that: 1) among the three specific sites selected in this study, the relative humidity shows subtle differences for the cloudy day and not much differences for the sunny day; 2) Sites 1 and 3 present approximate results, while their max absolute instantaneous differences between with site 2 are less than $15 \%$ in sunny day; 3 ) the relative humidity results are not only influenced by different sites but also the radiation effect, because the humidity measured sensors are directly exposed to the outside environment (Fig. 2). In summary, the wind speed and globe temperature difference between Site 2 and other two sites are the most obvious. This occurrence of amplified wind and lowered thermal radiation at Site 2 is favorable for its thermal comfort condition. 


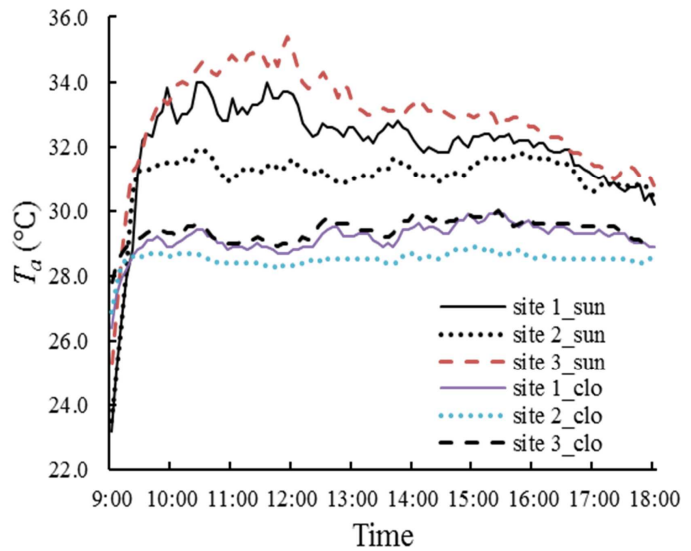

(1) Air temperature

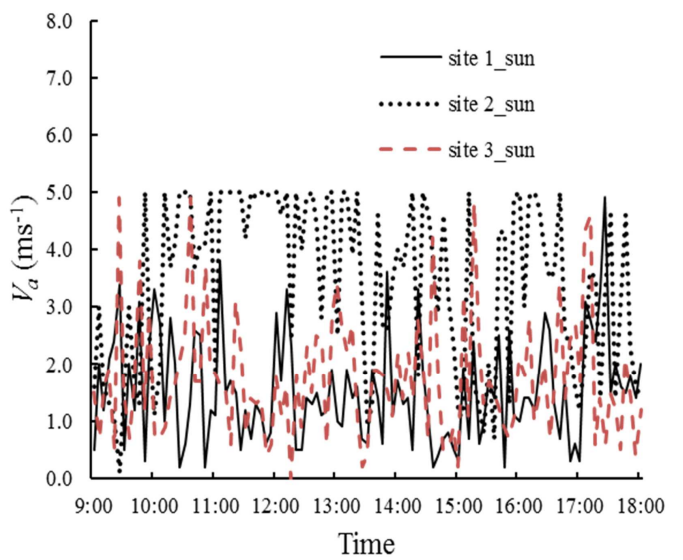

(3) Wind speed during a sunny day

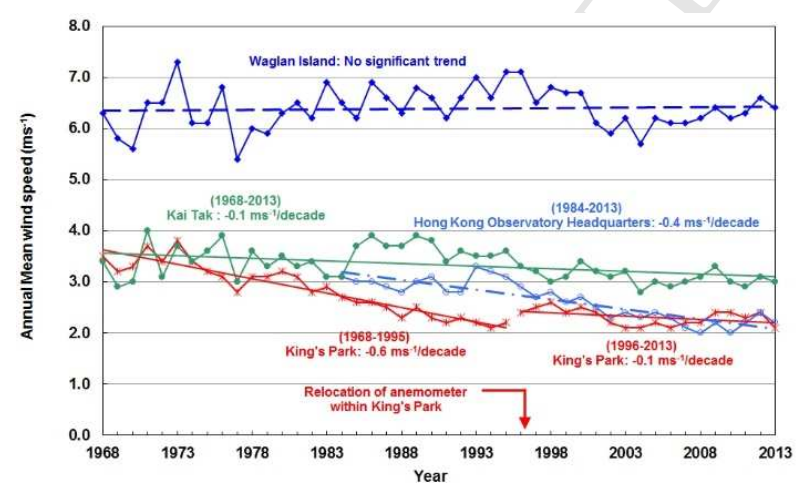

(5) Annual mean wind speed in Hong Kong

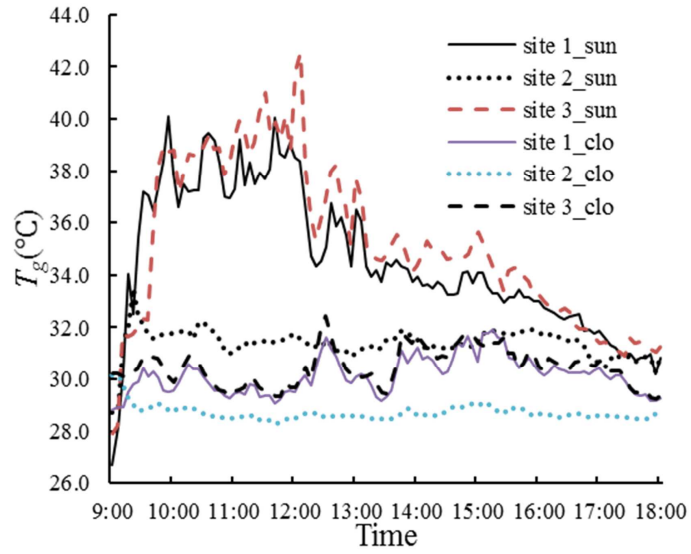

(2) globe temperature

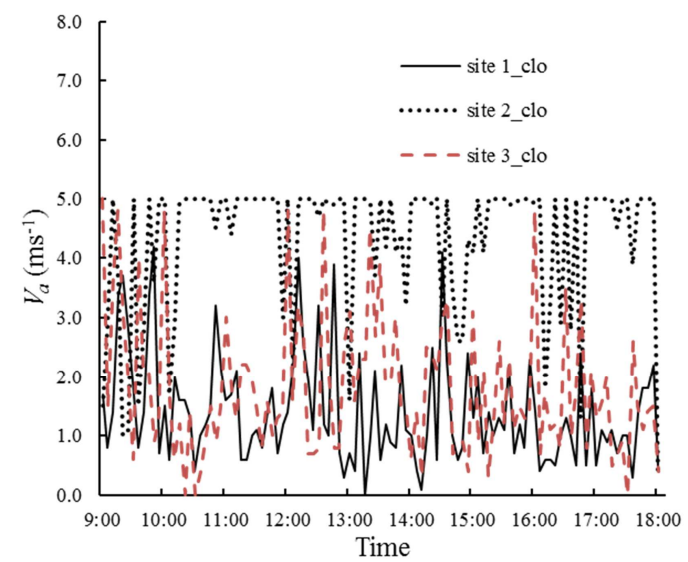

(4) Wind speed during a cloudy day

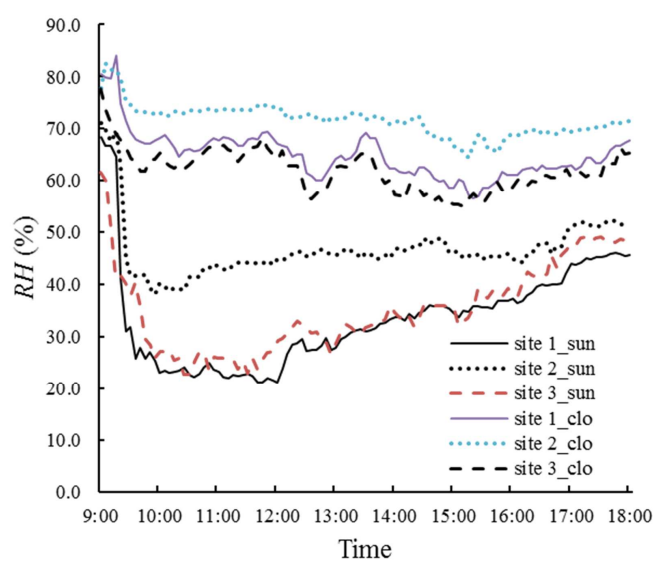

(6) Relative humidity

Fig. 4. Environmental parameter variations obtained from simultaneous monitoring: (1) air temperature, and (2) globe temperature on the two sample days; (3) wind speed during a sunny 
day, and (4) during a cloudy day; (5) annual mean wind speed in Hong Kong; (6) relative humidity.

\subsection{Thermal comfort comparisons in terms of PET}

Fig. 5 presents the instantaneous $P E T$ values calculated from the monitored environmental parameters at the three sites on both the sunny and cloudy days. For this calculation, the physiological assumption is that the pedestrian is a 25 years old male $(1.75 \mathrm{~m}$ and $75 \mathrm{~kg})$ with the clothing level of 0.5 clo and the internal heat production of $80 \mathrm{~W}$ which is based on the authors' observations and the suggested values of ISO 7730 [58] and ASHRAE Standard 55[59]. It can be observed that for both days the PET values are much lower at Site 2. It should be noted that, because the wind at Site 2 has exceeded the upper bound of the anemometer, $5 \mathrm{~m} / \mathrm{s}$ was used in calculating the PET in many data points so that the PET values have been higher-biased. Evidently Site 2 provides a much better thermal condition than the other two sites though it is still ranked as a slightly warm condition for European people, or slight heat-stress to moderate stress condition for East-asian people according to Table 1[31]. The PET difference at Site 1 and Site 3 appears negligible, and both were at hot conditions on the sunny day and warm conditions on the cloudy day, imposing strong and moderate heat stress.

As shown in Table 1, irrespective of the real environmental and individual conditions, the thermally perceivable PET difference is always either 3 or $2.5{ }^{\circ} \mathrm{C}$. The real question is if the required environmental parameter changes to cause the same PET change would vary under different base conditions. To appreciate this variation, we evaluated the environmental parameter changes that can cause the same PET change $(\triangle P E T=3)$ at the actual measured condition at Site 1 , and the required environmental parameter changes (thermally-perceivable environmental parameters' differences) are found to be $3.2^{\circ} \mathrm{C}, 6^{\circ} \mathrm{C}$ and $-1.3 \mathrm{~m} / \mathrm{s}$ respectively for the air temperature, radiant temperature and wind speed, which are respectively $46.7 \%, 9 \%$ and 0 different from those at the standard condition of $23{ }^{\circ} \mathrm{C}$ and $0.1 \mathrm{~m} / \mathrm{s}$, clo $=0.9$. Therefore, the thermally-perceivable environmental parameter differences calculated from the actual PET base condition can be used in the denominator of Equations (2) if a more accurate estimation is needed.

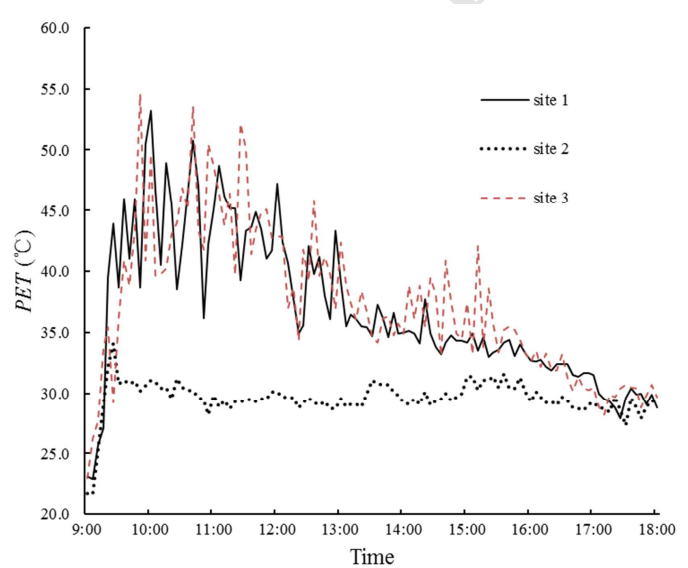

(1) Sunny day

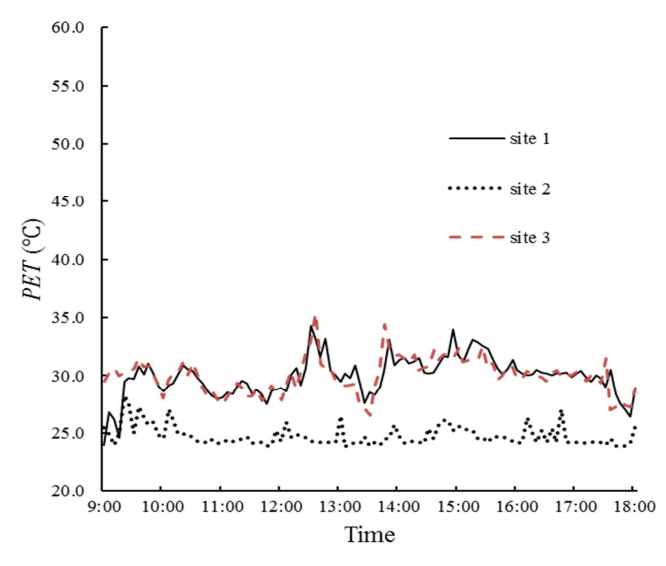

(2) Cloudy day 
Fig.5. PET calculated from environmental parameters monitored at pedestrian levels at the three sites on two sample summer days.

\subsection{Normalized environmental parameter differences}

Using Equation 1, 2, 3 and 4, the instantaneous environmental parameter differences between Sites 1 and 2 as well as Sites 1 and 3 were calculated. Then the daily average, maximum and minimum, and finally normalization for the two study days are presented in Fig.6 and 7. Two sets of data are presented in the figures, calculated respectively using the thermal parameters' changes that are required to cause a PET change of $3{ }^{\circ} \mathrm{C}$ and $2{ }^{\circ} \mathrm{C}$ (Table 1 ), considering the findings of Lin and Matzarakis [31] about the different thermal comfort perception for the Taiwan climate, which is similar to that of Hong Kong.

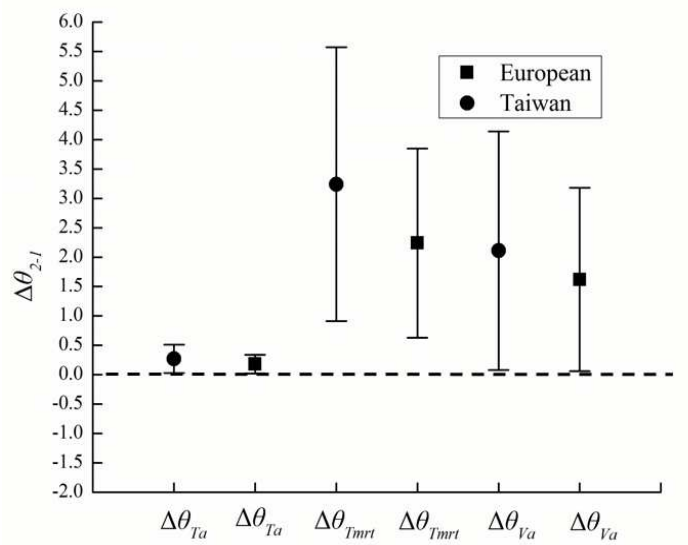

(1) sunny day

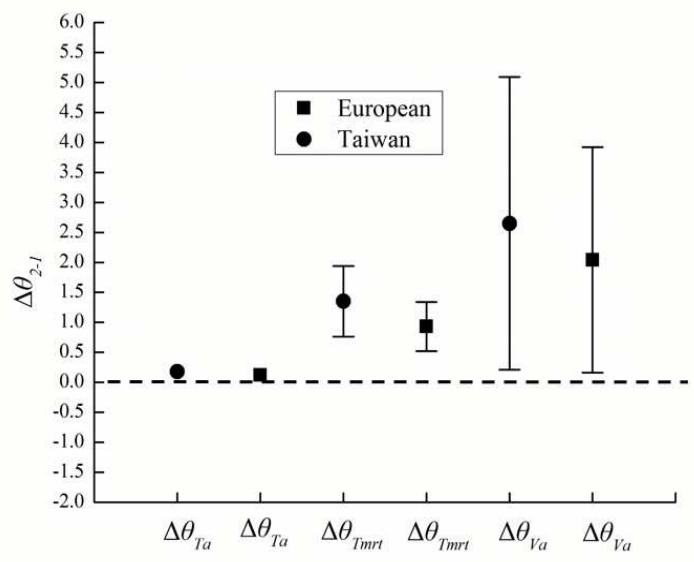

(2) cloudy day

Fig. 6. Normalized environmental parameter differences $T_{a}, T_{m r t}$ and $V_{a}$ (using two thermal perception differences: European and subtropical Asian regions as Taiwan) between Site 2 and Site 1 at pedestrian level on the two sample summer days.

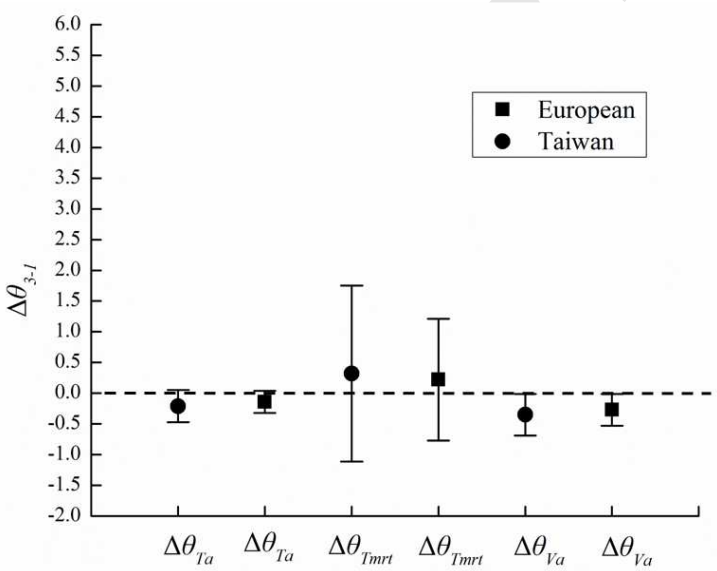

(1) sunny day

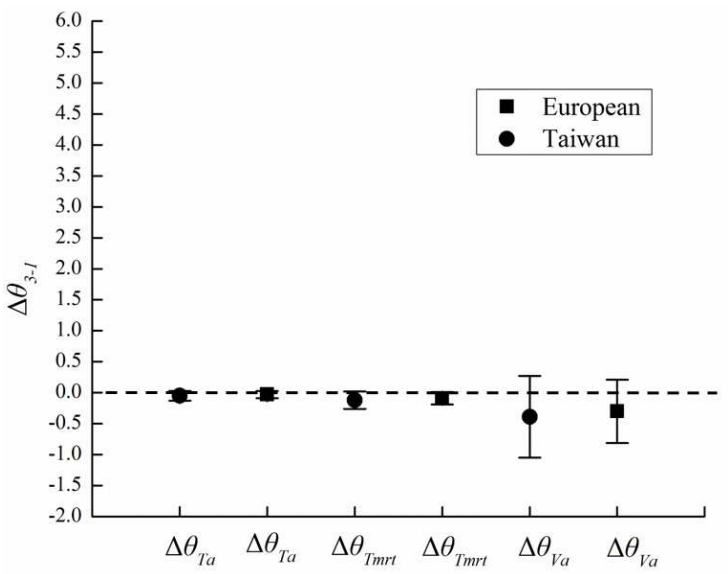

(2) cloudy day

Fig. 7. Normalized environmental parameter differences $T_{a}, T_{m r t}$ and $V_{a}$ (using two thermal perception differences: European and subtropical Asian regions as Taiwan) between Site 3 and Site 1 at pedestrian level on the two sample summer days. 
Apparently, the normalized air temperature differences between any two of the three sites are close to zero, indicating that air temperature difference is not a causal factor of the PET difference, on both the sunny and cloudy days. Between Sites 1 and 2, it appears that wind and radiant temperature differences have equal effects in producing the PET difference, with a slightly larger effect due to radiant temperature difference on the sunny day, with $\Delta \theta_{v a}=1.6$ for European set and 2.1 for subtropical regions set (e.g. Taiwan), and $\Delta \theta_{T m r t}=2.2$ for European and 3.2 for subtropical regions respectively; whereas on the cloudy day the wind speed difference carries more weight on PET, with $\Delta \theta_{v a}=2.0$ for European and 2.6 for subtropical regions, and $\Delta \theta_{T m r t}=0.9$ for European and 1.3 for subtropical regions respectively. On both days, wind amplification and shading effects both contributed significantly in improving the thermal comfort in the open space underneath the elevated building blocks.

For Sites 1 and 3, the instant PET values are very close to each other as shown in Fig. 5. Accordingly in Fig. 7, the two day-averages of the normalized radiant temperature $\Delta \theta_{\text {Tmrt }}$ ranges from 0to 0.3, and wind differences $\Delta \theta_{v a}$ ranges from -0.2 to -0.4 , indicating that the radiant temperature and wind speed are only subtly different, while mean radiant temperature makes Site 1 slightly warmer than Site 3, but lower wind in Site 3 makes it warmer than Site 1.

\section{Conclusions and discussions}

This preliminary study during the past summer confirmed the hypothesis that significantly different thermal comfort conditions exist within a precinct of the scale of 200 meters. In particular the thermal comfort conditions in the semi-open space underneath an elevated building block are apparently much better than other places nearby. The newly defined normalized environmental parameter differences are useful to identify if a particular environmental parameter is producing the PET difference. Further follow-up study will be undertaken to investigate the utilization frequency of these different places, though anecdotal evidences are available. Obviously the considerations would be different for cities in other climatic zones, and in general both summer and winter conditions need to be considered. Such real-life onsite monitoring and analysis would be helpful for the formulation of planning and design guidelines.

\section{Acknowledgements}

The authors wish to thank Ms WU Yan and Miss QIAN Xueni in helping manning the weather stations and collecting the data and Mr Kenny HUNG in preparing and calibrating the instruments used. Mr LIU Jianlin is funded by a UGC studentship.

\section{References}

[1] Hakim AA, Petrovitch H, Burchfiel CM, Ross GW, Rodriguez BL, White LR, et al. Effects of Walking on Mortality among Nonsmoking Retired Men. New England Journal of Medicine. 1998;338:94-9.

[2] Hass-Klau C. A review of the evidence from Germany and the UK. Transport Policy. 1993;1:21-31.

[3] Gehl J. Life between buildings: using public space. New York: Van Nostrand Reinhold; 1987.

[4] Maruani T, Amit-Cohen I. Open space planning models: A review of approaches and methods. Landscape and Urban Planning. 2007;81:1-13. 
[5] Givoni B, Noguchi M, Saaroni H, Pochter O, Yaacov Y, Feller N, et al. Outdoor comfort research issues. Energy and Buildings. 2003;35:77-86.

[6] Stathopoulos T, Wu H, Zacharias J. Outdoor human comfort in an urban climate. Building and Environment. 2004;39:297305.

[7] Mochida A, Lun IYF. Prediction of wind environment and thermal comfort at pedestrian level in urban area. Journal of Wind Engineering and Industrial Aerodynamics. 2008;96:1498-527.

[8] Chen L, Ng E. Outdoor thermal comfort and outdoor activities: A review of research in the past decade. Cities. 2012;29:11825.

[9] Yang LN, Li YG. City ventilation of Hong Kong at no-wind conditions. Atmospheric Environment. 2009;43:3111-21.

[10] Ng E. Policies and technical guidelines for urban planning of high-density cities - air ventilation assessment (AVA) of Hong Kong. Building and Environment. 2009;44:1478-88.

[11] Ng E, Cheng V. Urban human thermal comfort in hot and humid Hong Kong. Energy and Buildings. 2012;55:51-65.

[12] Givoni B. Man, Climate and architecture. New York : Elsevier; 1969.

[13] Nikolopoulou M, Baker N, Steemers K. Thermal comfort in outdoor urban spaces: Understanding the human parameter. Solar Energy. 2001;70:227-35.

[14] Nikolopoulou M, Lykoudis S. Thermal comfort in outdoor urban spaces: Analysis across different European countries. Building and Environment. 2006;41:1455-70.

[15] Lin TP. Thermal perception, adaptation and attendance in a public square in hot and humid regions. Building and Environment. 2009;44:2017-26.

[16] Ali-Toudert F, Djenane M, Bensalem R, Mayer H. Outdoor thermal comfort in the old desert city of Beni-Isguen, Algeria. Climate Research. 2005;28:243-56.

[17] Cheng V, Ng E. Thermal Comfort in Urban Open Spaces for Hong Kong. Architectural Science Review. 2006;49:236-42.

[18] Johansson E. Influence of urban geometry on outdoor thermal comfort in a hot dry climate: A study in Fez, Morocco. Building and Environment. 2006;41:1326-38.

[19] Johansson E, Emmanuel R. The influence of urban design on outdoor thermal comfort in the hot, humid city of Colombo, Sri Lanka. International Journal of Biometeorology. 2006;51:119-33.

[20] Lin TP, Matzarakis A, Hwang RL. Shading effect on long-term outdoor thermal comfort. Building and Environment. 2010;45:213-21.

[21] Thorsson S, Honjo T, Lindberg F, Eliasson I, Lim EM. Thermal comfort and outdoor activity in Japanese urban public places. Environment and Behavior. 2007;39:660-84.

[22] Ali-Toudert F, Mayer H. Numerical study on the effects of aspect ratio and orientation of an urban street canyon on outdoor thermal comfort in hot and dry climate. Building and Environment. 2006;41:94-108.

[23] Chen H, Ooka R, Harayama K, Kato S, Li XF. Study on outdoor thermal environment of apartment block in Shenzhen, China with coupled simulation of convection, radiation and conduction. Energy and Buildings. 2004;36:1247-58.

[24] Berkovic S, Yezioro A, Bitan A. Study of thermal comfort in courtyards in a hot arid climate. Solar Energy. 2012;86:117386.

[25] Nagano K, Horikoshi T. New index indicating the universal and separate effects on human comfort under outdoor and nonuniform thermal conditions. Energy and Buildings. 2011;43:1694-701.

[26] Pickup J, de Dear R. An outdoor thermal comfort index (OUT_SET*)-part I-the model and its assumptions. In: Biometeorology and urban climatology at the turn of the millennium Selected papers from the Conference ICB-ICUC1999, de Dear R, Kalma J, Oke T,and Auliciems, Sydney; 1999, pp. 279-83.

[27] De Dear R, Pickup J. An Outdoor Thermal Environment Index (OUT_SET*)-Part II-Applications. In: Biometeorology and urban climatology at the turn of the millennium Selected papers from the Conference ICB-ICUC1999, de Dear R, Kalma J, Oke T,and Auliciems, Sydney; 1999, pp. 258-90.

[28] Fanger PO. Thermal comfort : analysis and applications in environmental engineering. New York : McGraw-Hill; 1972.

[29] Gagge AP, Fobelets A, Berglund L. A standard predictive index of human response to the thermal environment. ASHRAE Trans. 1986;92:709-31.

[30] Höppe P. The physiological equivalent temperature-a universal index for the biometeorological assessment of the thermal environment. International Journal of Biometeorology. 1999;43:71-5.

[31] Lin TP, Matzarakis A. Tourism climate and thermal comfort in Sun Moon Lake, Taiwan. International Journal of Biometeorology. 2008;52:281-90.

[32] Blazejczyk K, Epstein Y, Jendritzky G, Staiger H, Tinz B. Comparison of UTCI to selected thermal indices. International Journal of Biometeorology. 2012;56:515-35.

[33] Jendritzky G, de Dear R, Havenith G. UTCI-Why another thermal index? International Journal of Biometeorology. 2012;56:421-8.

[34] Kenny NA, Warland JS, Brown RD, Gillespie TG. Part B: Revisions to the COMFA outdoor thermal comfort model for application to subjects performing physical activity. International Journal of Biometeorology. 2009;53:429-41.

[35] Matzarakis A, Mayer H, Iziomon MG. Applications of a universal thermal index: physiological equivalent temperature. International Journal of Biometeorology. 1999;43:76-84.

[36] Mayer H, Holst J, Dostal P, Imbery F, Schindler D. Human thermal comfort in summer within an urban street canyon in Central Europe. Meteorologische Zeitschrift. 2008;17:241-50. 
[37] Lin TP, de Dear R, Hwang RL. Effect of thermal adaptation on seasonal outdoor thermal comfort. International Journal of Climatology. 2011;31:302-12.

[38] Lin TP, Tsai KT, Liao CC, Huang YC. Effects of thermal comfort and adaptation on park attendance regarding different shading levels and activity types. Building and Environment. 2013;59:599-611.

[39] Knez I, Thorsson S. Thermal, emotional and perceptual evaluations of a park: Cross-cultural and environmental attitude comparisons. Building and Environment. 2008;43:1483-90.

[40] Jeong SY, Yoon SH. Method to quantify the effect of apartment housing design parameters on outdoor thermal comfort in summer. Building and Environment. 2012;53:150-8.

[41] Yin JF, Zheng YF, Wu RJ, Tan JG, Ye DX, Wang W. An analysis of influential factors on outdoor thermal comfort in summer. International Journal of Biometeorology. 2012;56:941-8.

[42] Zhou Z, Chen H, Deng QL, Mochida A. A Field Study of Thermal Comfort in Outdoor and Semi-outdoor Environments in a Humid Subtropical Climate City. Journal of Asian Architecture and Building Engineering. 2013;12:73-9.

[43] Lai DY, Zhou CB, Huang JX, Jiang Y, Long ZW, Chen QY. Outdoor space quality: A field study in an urban residential community in central China. Energy and Buildings. 2014;68:713-20.

[44] Lai DY, Guo DH, Hou YF, Lin CY, Chen QY. Studies of outdoor thermal comfort in northern China. Building and Environment. 2014;77:110-8.

[45] Ali-Toudert F, Mayer H. Effects of asymmetry, galleries, overhanging facades and vegetation on thermal comfort in urban street canyons. Solar Energy. 2007;81:742-54.

[46] Ali-Toudert F, Mayer H. Thermal comfort in an east-west oriented street canyon in Freiburg (Germany) under hot summer conditions. Theoretical Applied Climatology. 2007;87:223-37.

[47] Hwang RL, Lin TP, Matzarakis A. Seasonal effects of urban street shading on long-term outdoor thermal comfort. Building and Environment. 2011;46:863-70.

[48] Hwang RL, Lin TP. Thermal comfort requirements for occupants of semi-outdoor and outdoor environments in hot-humid regions. Architectural Science Review. 2007;50:357-64.

[49] Lin TP, Tsai KT, Hwang RL, Matzarakis A. Quantification of the effect of thermal indices and sky view factor on park attendance. Landscape and Urban Planning. 2012;107:137-46.

[50] Kántor N, Unger J. Benefits and opportunities of adopting GIS in thermal comfort studies in resting places: An urban park as an example. Landscape and Urban Planning. 2010;98:36-46.

[51] Xi TY, Li Q, Mochida A, Meng QL. Study on the outdoor thermal environment and thermal comfort around campus clusters in subtropical urban areas. Building and Environment. 2012;52:162-70.

[52] ISO. International Standard 7726. Ergonomics of the thermal environment -Instruments for measuring physical quantities. Geneva: International Standard Organization; 1998.

[53] Mayer H, Höppe P. Thermal comfort of man in different urban environments. Theoretical Applied Climatology. 1987;38:439.

[54] VDI. Methods for the human biometeorological evaluation of climate and air quality for the urban and regional planning. VDI guideline 3787. Berlin: Beuth; 1998.

[55] Matzarakis A, Rutz F, Mayer H. Modelling radiation fluxes in simple and complex environments-application of the RayMan model. International Journal of Biometeorology. 2007;51:323-34.

[56] Matzarakis A, Rutz F, Mayer H. Modelling radiation fluxes in simple and complex environments: basics of the RayMan model. International Journal of Biometeorology. 2010;54:131-9.

[57] Sasaki K, Mayer H, Mochida A, Uchida M, Tonouchi T. Field measurement on thermal comfort in outdoor locations comparison of SET* and PET based on questionnaire survey. In: Proceedings of the 7th International Conference on Urban Climate, Yokohama, Japan; 2009.

[58] ISO. International Standard 7730. Ergonomics of the thermal environment - Analytical determination and interpretation of thermal comfort using calculation of the PMV and PPD indices and local thermal comfort criteria. Geneva: International Standard Organization; 2005.

[59] ASHRAE. ASHRAE Standard 55-2013.Thermal Environmental Conditions for Human Occupancy. American Society of Heating, Refrigeration and Air-conditioning Engineers; 2013. 
Highlights

Outdoor thermal comfort conditions vary significantly within a built-up precinct

Outdoor local cooling spots for summer thermal comfort can be created by design

Summer thermal comfort underneath an elevated building is significantly better

- PET based thermally-perceivable environmental parameter differences are defined

- The new dimensionless indices are useful to identify the causal factor 